OPEN ACCESS

Edited by:

Jarostaw Woliński,

Kielanowski Institute of Animal

Physiology and Nutrition (PAN), Poland

Reviewed by:

Andreas Stengel,

Charité - Universitätsmedizin Berlin,

Germany

Huansheng Yang,

Hunan Normal University, China

*Correspondence:

Zehava Uni

zehava.uni@mail.huji.ac.il

Specialty section:

This article was submitted to Gastrointestinal Sciences, a section of the journal

Frontiers in Physiology

Received: 19 August 2020 Accepted: 27 November 2020 Published: 17 December 2020

Citation:

Reicher N, Melkman-Zehavi T,

Dayan J and Uni Z (2020) It's All

About Timing: Early Feeding Promotes Intestinal Maturation by Shifting the Ratios of Specialized Epithelial Cells in Chicks.

Front. Physiol. 11:596457. doi: 10.3389/fphys.2020.596457

\section{It's All About Timing: Early Feeding Promotes Intestinal Maturation by Shifting the Ratios of Specialized Epithelial Cells in Chicks}

\author{
Naama Reicher, Tal Melkman-Zehavi, Jonathan Dayan and Zehava Uni* \\ Department of Animal Science, The Robert H. Smith, Faculty of Agriculture, Food and Environment, The Hebrew University \\ of Jerusalem, Rehovot, Israel
}

The small intestine (SI) of chicks (Gallus gallus) matures rapidly during the initial post-hatch period and acquires digestive, absorptive, and secretive capabilities. The effects of the timing of first feeding on the quantities and distribution of specialized epithelial cells, which generate and maintain SI morphology and functionality, have not yet been examined. In this study, we identified specialized SI epithelial cell sub-types, including stem, progenitor, proliferating, and differentiated cells within crypts and villi of chicks during the first 10 days post-hatch, by in situ hybridization (ISH), immunofluorescence (IF), and histochemical staining. We then examined their quantities and ratios between day of hatch and d10 in chicks that were fed upon hatch [early feeding (EF)], compared to chicks that were fed $24 \mathrm{~h}$ post-hatch [delayed feeding (DF)]. Results showed that EF increased total cell quantities in the crypts and villi at days $1,3,7$, and 10 , compared to DF $(p<0.0001)$. At d3, EF, in comparison to DF, decreased crypt stem cell proportions $(p<0.0001)$, increased crypt proliferating $(p<0.01)$ and differentiated $(p<0.05)$ cell proportions, and increased villus enterocyte proportions $(p<0.01)$. By d10, EF increased both the quantities and proportions of villus enterocytes and goblet cells, compared to DF. We conclude that feeding upon hatch, compared to 24 h-delayed feeding, enhanced SI maturation and functionality by increasing the quantities and proportions of proliferating and differentiated cells, thus expanding the digestive, absorptive, and secretive cell populations throughout the initial post-hatch period.

Keywords: intestine, first feeding, epithelial cells, chick, maturation

\section{INTRODUCTION}

The small intestinal (SI) mucosa is lined with a specialized epithelium, comprised of various cell sub-types, which undergo constant renewal and change. Functional SI epithelial cells are organized in lumen-facing villi, and are responsible for nutrient digestion and absorption, mucin secretion, chemosensation, and hormonal signaling. Intestinal stem cells reside in crypts at the bottom of each villus, and maintain a balance between production of progenitor cells and self-renewal. Progenitor cells proliferate, differentiate, and migrate along the crypt-villus axis, giving rise to all functional cells (Potten and Loeffler, 1990; Gehart and Clevers, 2019). 
Cellular lineages, niche characterization and regulatory processes within the SI epithelium have been widely researched in human and mouse models (Blache et al., 2004; Barker et al., 2007; Carulli et al., 2014; Moor et al., 2018; Bahar Halpern et al., 2020). However, in chicken, cell sub-type dynamics within the SI epithelium is generally under-characterized. Few studies have indicated both similarities and differences in the spatial organization of the SI epithelial cell sub-types between chicken and humans or mice. For example, in a manner similar to mice and humans, stem cells are restricted to the crypts and enterocytes are found along the villi in chicken (Zhang and Wong, 2017, 2018). However, in contrast to mice and humans, proliferating and immune cells in chicken were observed along the villi, as well as within the crypts (Uni et al., 1998; Wang et al., 2016; Bar Shira and Friedman, 2018). Being a precocial species, newly hatched chicks undergo intensive intestinal maturation processes, in order to make a rapid transition from egg yolk-based nutrition to external feeding (Noy and Sklan, 1998; Uni et al., 1999; Yadgary et al., 2010). This transition occurs during the initial 10 days post-hatch and is governed by morphological, cellular, and molecular changes in the SI epithelium, including cell proliferation, formation of crypts, and elongation of villi. Functional cells develop along the villi, and mainly consist of enterocytes, expressing nutrient transporters and digestive enzymes, and protective mucin-secreting goblet cells, in a 5:1 ratio (Uni et al., 2000, 2003a,b; Gilbert et al., 2007; Zwarycz and Wong, 2010; Speier et al., 2012). SI development and functionality during this initial 10 days period is highly correlated with long-term performance parameters, including feed intake, body weight, and mortality rates (Sklan, 2001). In poultry production, chicks are susceptible to $24-72 \mathrm{~h}$ delays in the timing of first feeding, due to broad hatching windows, hatchery treatments, and transportation. Research shows that delayed first feeding in chicks disrupts SI development by limiting crypt depths and villus heights, altering epithelial proliferation patterns, dysregulating differentiation-associated genes, and disrupting mucin dynamics (Geyra et al., 2001, 2002; Uni et al., 2003a, de Jong et al., 2017). Long-term systematic effects of delayed first feeding include impaired nutrient utilization, altered regulation of metabolic pathways, disrupted barrier functions, and impaired gut immunity, all of which jeopardize animal welfare, impair performance in increase mortality rates (Bigot et al., 2003; Bar Shira et al., 2005; de Jong et al., 2017; Hicks et al., 2019; Payne et al., 2019; Proszkowiec-weglarz et al., 2020). In this study, we aimed to evaluate how the timing of first feeding of chicks influences the quantities and distribution of specialized SI epithelial cell sub-types during the initial 10 days post-hatch. Cell sub-types examined were stem, progenitor, proliferating, and differentiated cells, which provide basic input for the capacity of the SI to

\footnotetext{
Abbreviations: BSA, Bovine serum albumen; DAPI, 4',6-diamidino-2-phenylindole; DAB, 3,3'-Diaminobenzidine; IF, Immunofluorescence; ISH, In situ hybridization; Lgr5, Leucin-rich repeat-containing G-protein coupled receptor 5; PBS, Phosphate buffered saline; PCNA, Proliferating cell nuclear antigen; PepT1, Peptide transporter 1; PBST, Phosphate buffered saline, $0.1 \%$ Tween $^{\star}$; RT, Room temperature; SEM, standard error mean; SI, Small intestine.
}

generate and maintain digestive, absorptive, and immune functionality. We located these cell sub-types using in situ hybridization (ISH) for the stem cell marker leucine-rich repeatcontaining G-protein coupled receptor 5 (Lgr5; Barker et al., 2007) and enterocyte marker Peptide transporter 1 (PepT1; Fei et al., 2000); immunofluorescence (IF) for the stem/progenitor cell marker SRY-box transcription factor 9 (Sox9; Blache et al., 2004), the proliferation marker proliferating cell nuclear antigen (PCNA; Kubben et al., 1994) and enterocyte marker fatty acid binding protein (FABP; Storch and Corsico, 2008); and histochemical staining for goblet cells. We then examined the effects of immediate post-hatch access to feed [early feeding (EF)] and a $24 \mathrm{~h}$ delay in the timing of first feeding [delayed feeding (DF)], corresponding to the minimal delay of first feeding in current poultry commercial practice, on specific cell sub-type abundances and ratios throughout the critical first 10 days post-hatch period.

\section{MATERIALS AND METHODS}

\section{Animals and Experimental Design}

Fertile Cobb500 broiler eggs $(n=70)$ were obtained from a commercial hatchery (Brown Ltd., Hod-Hasharon, Israel) at day of lay and incubated in a Petersime hatchery at the Faculty of Agriculture of the Hebrew University, under standard conditions $\left(37.8^{\circ} \mathrm{C}, 60 \%\right.$ relative humidity) for 21 days. Hatching window was monitored from the beginning of embryonic day 20 (e20). Fifty four chicks of equal weights $(42.2 \pm 3.2 \mathrm{gr}$ SEM), that hatched between e20.5 and e21, were selected for the experimental procedures. Unhatched eggs (12\% of total incubated eggs) and chicks which hatched after the end of e21 were excluded from the experiment. At hatch, six chicks were processed for histological procedures. The remaining 48 chicks were transferred to brooders at the Faculty of Agriculture of the Hebrew University and were randomly divided into two groups, each subject to a different timing of first feeding: EF chicks received initial access to feed and water immediately upon arrival to brooder (day of Hatch) and DF chicks received initial access to feed and water $24 \mathrm{~h}$ after arrival to brooder (d1). Both groups were fed with a standard commercial starter diet (Brown feedmill, Kaniel, Israel), formulated according to NRC (National Research Council, 1994) recommendations. After granting initial access to feed, both groups were fed ad-libitum. Tissue sampling for histological procedures was conducted at days $1,3,7$, and 10 on six chicks from each group.

\section{Tissue Sampling}

Sampled chicks were euthanized by $\mathrm{CO}_{2}$, according to established guidelines for animal care and handling and were approved by the Hebrew University Institutional Animal Care and Use Committee (IACUC:AG-17-15355-2). The SI jejunum segment ( $1 \mathrm{~cm}$ piece from the midpoint between the duodenal loop and Meckel's diverticulum) was immediately excised from each chick, rinsed in phosphate buffered saline (PBS), and fixed in $3.7 \%$ formaldehyde in PBS ( $\mathrm{pH} 7.4$ ) for $24 \mathrm{~h}$ at room temperature (RT). Tissues was then rinsed out in PBS, dehydrated in grated series of ethanol, cleared by Histochoice ${ }^{\circledR}$ 
(Sigma-Aldrich, Rehovot, Israel) and embedded in Paraplast ${ }^{\circledR}$ (Sigma-Aldrich, Rehovot, Israel). Tissue blocks were sectioned $5 \mu \mathrm{m}$ thick with a microtome, and mounted on SuperFrost Plus $^{\mathrm{TM}}$ glass slides (Bar-Naor Ltd., Petah-Tikva, Israel).

\section{In situ Hybridization}

Jejunum sections were deparaffinized by Histochoice ${ }^{\circledR}$ (SigmaAldrich, Rehovot, Israel) and rehydrated in a graded series of ethanol. RNAscope ${ }^{\circledR}$ ISH was performed as described by Wang et al. (2012), using custom made probes and commercial kits (ACD, Newark, CA) according to the manufacturer's protocol. Lgr5 mRNA transcripts were hybridized using a Gg-Lgr5 probe (XM_425441.4, Cat. No. 480781) and detected using RNAscope 2.5 HD Kit-RED (Cat. No. 322350). PepT1 mRNA transcripts were hybridized using a Gg-SLC15A1 probe (NM_204365.1, Cat. No. 462341) and detected using RNAscope $2.5 \mathrm{HD}$ Kit-BROWN (Cat. No. 322300). All slides were counterstained with 50\% hematoxylin (Sigma-Aldrich, Rehovot, Israel). Results were validated using a positive control probe (Gg-PPIB, Cat. No 453371) and a negative control probe DapB (Cat. No. 310043).

\section{Histochemical and Immunofluorescent Staining}

Jejunum sections were deparaffinized by Histochoice ${ }^{\circledR}$ (SigmaAldrich, Rehovot, Israel) and rehydrated in a graded series of ethanol. For goblet cell quantification, slides were stained with Alcian blue (AB; A5268, Sigma-Aldrich, Rehovot, Israel) and periodic acid Schiff (PAS; PAS staining kit 395B, Sigma-Aldrich, Rehovot, Israel), and sealed with Fluoromount $G$ with 4',6-diamidino-2-phenylindole (DAPI; Invitrogen, 00-4959). For immunostaining, antigen retrieval was performed by heating slides for $20 \mathrm{~min}$ in $\mathrm{pH} 5.5$ citrate buffer (Sigma-Aldrich, Rehovot, Israel). Sections were permeabilized in PBS with $0.1 \%$ Tween $^{\circledR}$ (Sigma-Aldrich, Rehovot, Israel; PBST), and blocked in $1 \%$ bovine serum albumin (BSA, Sigma-Aldrich, Rehovot, Israel) in PBS. Slides were incubated overnight at $4^{\circ} \mathrm{C}$ with primary antibodies in two separate combinations: (1) Rabbit anti-Sox9 (1:150, AB5535, Millipore) and mouse anti-PCNA (1:300, sc-56, Santa Cruz); (2) Goat anti-FABP (1:250, ab60272, Abcam) and mouse anti-PCNA (1:300, sc-56, Santa Cruz). Following washes in PBS and PBST, slides were incubated $1 \mathrm{~h}$ at RT with the following secondary antibodies: (1) Sox9: Donkey anti-Rabbit Alexa Fluor 488 (1:100, 711-545-152, Jackson ImmunoResearch Laboratories, Inc); PCNA: Donkey anti-mouse Cy3 (1:100, 715-165-150, Jackson ImmunoResearch Laboratories, Inc) and (2) FABP: Donkey anti-Goat Alexa Fluor 488 (A-11055, Invitrogen); PCNA: same as in (1). Slides were then washed in PBS and sealed with Fluoromount G with DAPI (00-4959, Invitrogen).

\section{Image Acquisition and Processing}

Images were acquired using a BX40 Olympus microscope (Waltham, MA, United States) wide-field microscope, connected to a DP73 camera, and processed in Cell Sense Imaging Software (version 1.16), using X10 and X40 objectives. Whole villi images were acquired by $\mathrm{EVOS}^{\circledR}$ FL Auto Imaging System (Thermo Fisher Scientific) using a X20 objective and image stitching. Images were post-processed for brightness/contrast adjustments using ImageJ software. RNAscope ${ }^{\circledR}$ ISH probe density per $\mu \mathrm{m}^{2}$ was calculated using $\mathrm{HALO}^{\circledR}$ software (version 2.2.1870). Villus and crypt cells were quantified by counting DAPI-stained nuclei in at least 10 villi and 10 crypt cells per chick (total of at least 30 villi and 30 crypt cells per group at each timepoint). Villus/crypt cell ratios were calculated by dividing the number of cells per villus by the number of cells per adjacent crypt in 6-7 villus-crypt units per chick (total of at least 20 units per group at each timepoint). Immunofluorescent cells within each villus (either $\mathrm{FABP}^{+} / \mathrm{PCNA}^{+}$or $\mathrm{FABP}^{+} / \mathrm{PCNA}^{-}$) and within each crypt (either Sox $9^{+} / \mathrm{PCNA}^{-}$, Sox $9^{+} / \mathrm{PCNA}^{+}$, Sox $9^{-} / \mathrm{PCNA}^{+}$, or Sox $\left.9^{-} / \mathrm{PCNA}^{-}\right)$were quantified in at least 10 villi and 10 crypt cells per chick (total of at least 30 villi and 30 crypt cells per group at each timepoint). Cell sub-type ratios were calculated by dividing the number of each cell sub-type by the number of DAPI-stained villus/crypt cells. Goblet cells were quantified by AB-PAS staining in at least 10 villi and 10 crypt cells per chick (total of at least 30 villi and $30 \mathrm{crypt}$ cells per group at each timepoint), and their ratios were calculated by dividing their quantities by the number of DAPIstained villus/crypt cells. Image acquisitions and processing were conducted by two unblinded observers.

\section{Statistical Analysis}

Data were analyzed using one-way ANOVA. Differences were considered significant at $p<0.05$. Student's $t$-test was conducted for detecting significant differences between EF and DF groups at each timepoint and significant differences were marked with an asterisk. Tukey-Kramer HSD test was conducted for detecting significant differences between ages within each group and significant differences were marked with different lowercase letters. Graphical data were expressed as mean \pm SEM. All statistical analyses were conducted with JMP Pro 14 software (SAS Institute, Cary, NC, United States).

\section{RESULTS}

Our experimental procedures were conducted on SI jejunum sections from chicks between the age of Hatch and day 10 (d10) belonging to two groups: EF chicks began feeding upon hatching and DF chicks began feeding $24 \mathrm{~h}$ post-hatch (Figure 1A). In order to evaluate the effects of the timing of first feeding on SI post-hatch development through morphological parameters, we quantified the total number of cells by DAPI nuclear staining within villi (Figure 1B) and crypts (Figure 1D) and measured villi heights and crypt depths (Figure 1G) in both groups between Hatch and d10. At d1, villus and crypt cell counts were significantly higher in EF chicks, compared to DF chicks ( $p<0.0001$ for both; Figures 1C,E). Interestingly, the total number of crypt cells in EF chicks at d1 was similar to that of chicks at Hatch, while DF chicks at d1 exhibited a significant decrease in crypt cell counts in comparison to 


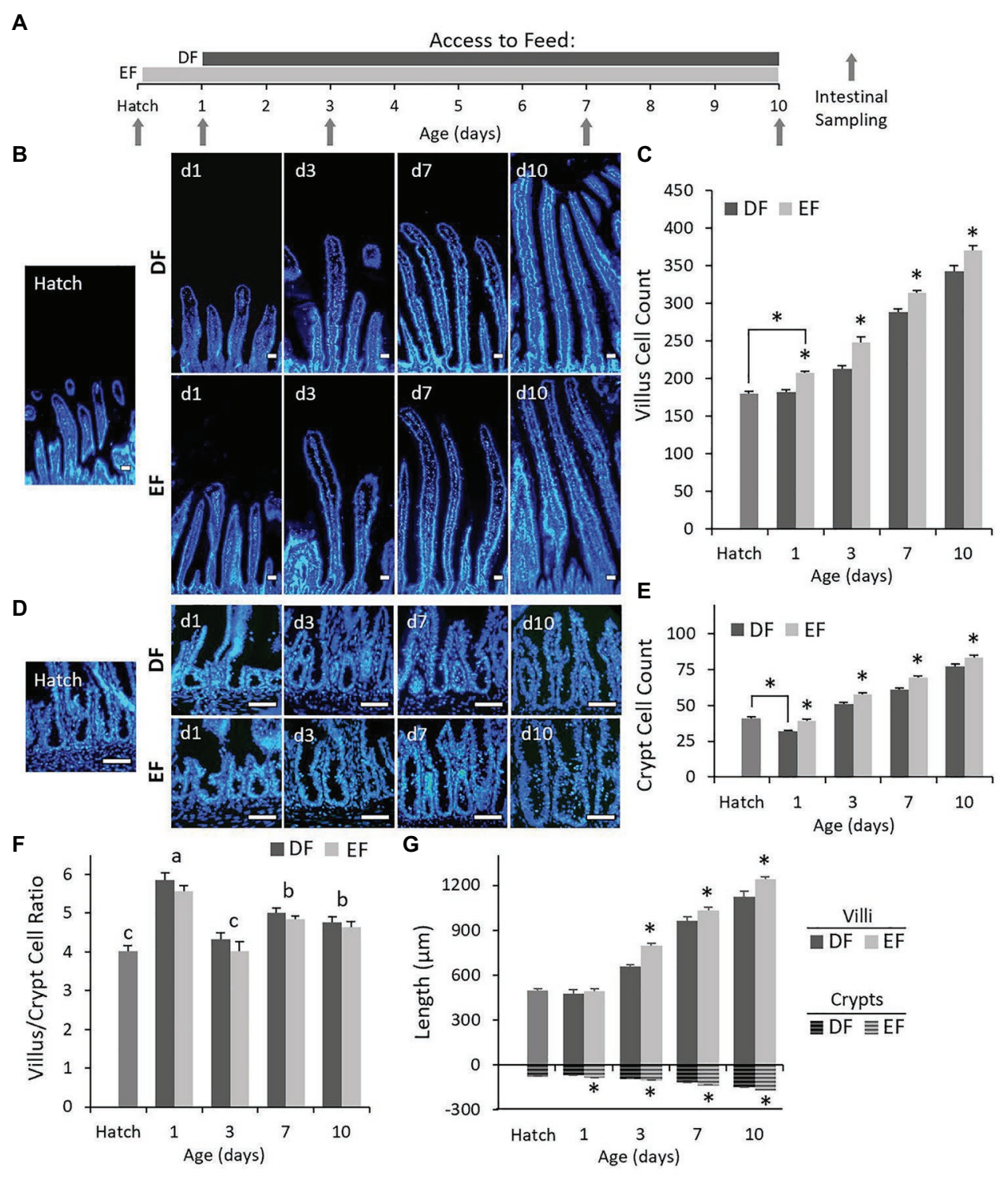

FIGURE 1 | Early feeding increases crypt and villi cell counts throughout post-hatch intestinal development. (A) Experimental timeline. Chicks at hatch were divided into two groups: EF chicks were fed upon hatch and delayed feeding chicks were fed 24 h post-hatch. Intestinal segments from both groups were sampled at Hatch (prior to feeding in both groups), d1 (prior to feeding in DF chicks), d3, d7, and d10. Villus (B) and crypt (D) cells were stained with 4',6-diamidino-2phenylindole (DAPI) from Hatch to d10 in DF and EF chicks. Scale bars are $50 \mu \mathrm{m}$. DAPI-stained villus (C) and crypt (E) cells were counted from Hatch to d10 in DF and EF chicks. Values are means + SEM, asterisks mark significant differences between DF and EF chicks for each age by $t$-test, $p<0.05$. (F) Ratios between villi cell counts and crypt cell counts from Hatch to d10 in DF and EF chicks. Ratios did not differ between DF and EF chicks. Letters mark significant differences between ages in values from both groups by Tukey-Kramer test, $p<0.05$. (G) Measurements of villi heights (solid-filled bars) and crypt depths (striped-bars) from Hatch to d10 in DF and EF chicks. Values are means + SEM, and asterisks mark significant differences between DF and EF chicks for each age by $t$-test.

chicks at Hatch $(p<0.0001$; Figures 1C,E). Crypt depth measurements were decreased accordingly in DF chicks compared to EF chicks $(p<0.0001)$ and chicks at Hatch $(p=0.0147$; Figure 1G). In contrast, the number of cells per villus at d1 in comparison to Hatch was significantly higher in EF chicks, but did change in DF chicks ( $p=0.0043$; Figure 1C). Surprisingly, villi lengths did not differ among DF chicks, EF chicks, and chicks at Hatch (Figure 1G). From d3 to d10, we observed an increase in villus and crypt cell counts in both groups, with cell numbers being consistently higher in EF chicks, compared to DF chicks, at all timepoints (villi: d1, $\mathrm{d} 3$, and $\mathrm{d} 7, p<0.0001$; d10, $p=0.0027$; crypts: $\mathrm{d} 1, p<0.0001$; $\mathrm{d} 3, p=0.003$; d10, $p=0.0067$; Figures 1C,E). Villi lengths and crypt depths increased accordingly (crypts: $\mathrm{d} 3, p=0.003$; d7, $p<0.0001$; d10, $p=0.0067$; villi: d3, $p<0.0001$; 7 , $p<0.0235, \mathrm{~d} 10, p=0.0032$; Figure 1G). The villus height to crypt depth ratio is an indicator of SI development, which may be measured through several methods (Wilson et al., 2018). 
Since this ratio represents the replenishment and turnover rate of differentiated villus cells (Potten and Loeffler, 1990), we calculated the villus cell to crypt cell ratio in order to assess the effects of the timing of first feeding on villus cell accumulation relative to crypt development. Results showed that at all timepoints, timing of first feeding did not affect the villus/crypt cell ratio (Figure 1F). However, a comparison of villus/crypt cell ratios from both groups between ages revealed significant changes with age: villus/crypt cell ratios were lowest at Hatch and $\mathrm{d} 3$, highest at $\mathrm{d} 1$ and reached a stable, intermediate level at d7, which was maintained at $\mathrm{d} 10$ ( $p<0.0001$; Figure 1F).

Next, we examined expression patterns of stem cell marker Lgr5 (Barker et al., 2007) and enterocyte marker PepT1 (Fei et al., 2000) by RNAscope ${ }^{\circledR}$ ISH, which allows specific and sensitive quantification of mRNA expression in a spatial context (Wang et al., 2012). Consistent with previous findings (Zhang and Wong, 2017, 2018), Lgr5 mRNA expression was restricted to crypts (Figures 2A,B) and PepT1 mRNA expression was located along the villi (Figures 2E,F) at Hatch. At d10, Lgr5 expression was mainly localized to the bottom third of the crypts in both DF and EF chicks (Figures 2C,D), and PepT1 expression was similar to that at Hatch Probe (Figures 2G,H). Probe density quantification at $\mathrm{d} 10$ revealed that Lgr5 expression did not differ between DF and EF chicks (Figure 2I), yet PepT1 expression was significantly higher in EF chicks, compared to DF chicks $(p<0.0001$; Figure 2J). These data suggest that by $\mathrm{d} 10$, EF enhances the enterocyte population within the villi, while the crypt stem cell population remains stable. Therefore, in order to examine whether the timing of first feeding affected cellular proliferation and differentiation from crypt-based stem cells into differentiated villi cells during post-hatch intestinal development, we examined co-localizations of stem/progenitor cell marker Sox9 (Blache et al., 2004), cytosolic enterocyte marker FABP (Storch and Corsico, 2008), and proliferation marker PCNA (Kubben et al., 1994) in crypt and villi cells by IF. We found that Sox9 expression was restricted to the bottom two-thirds of crypt cells, FABP was expressed exclusively in villi cells, and PCNA was co-expressed in cells of both
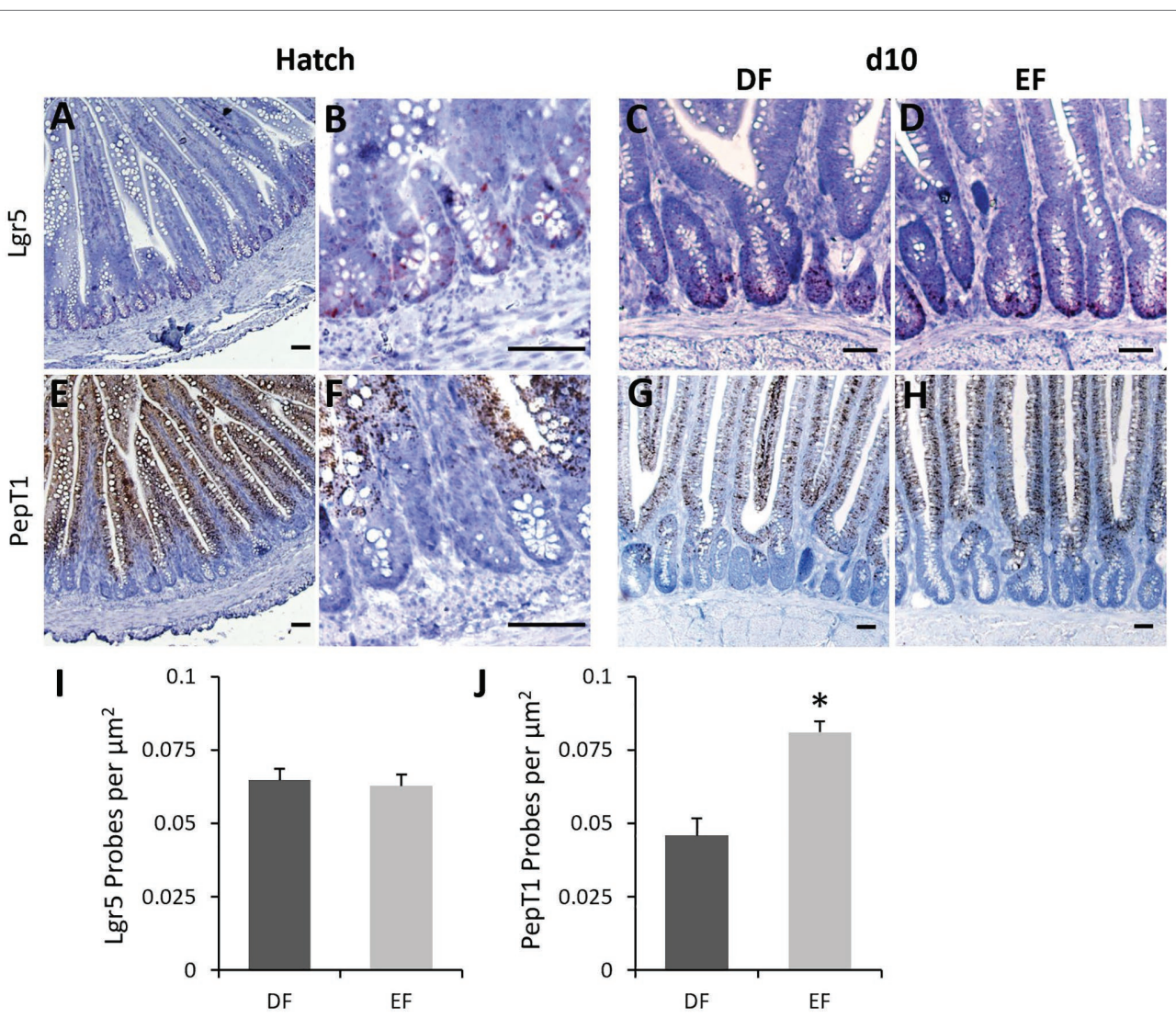

FIGURE 2 | Early feeding increases villus PepT1 expression and does not affect crypt Lgr5 expression at d10. mRNA expression of the stem cell marker Leucinrich repeat-containing G-protein coupled receptor 5 (Lgr5) detected by RNAscope in situ hybridization (ISH) at Hatch (A, X100 magnification; B, crypt zone by X400 magnification) and d10, in DF (C) and EF (D) chicks (X400 magnification) is restricted to crypts at both timepoints. Probes were detected with fast-red, and tissues were counterstained with 50\% hematoxylin. mRNA expression of the enterocyte marker Peptide transporter 1 (PepT1) detected by RNAscope (ISH) at Hatch (E, X100 magnification; $\mathbf{F}$, crypt zone by X400 magnification) and d10, in DF (G) and EF (H) chicks (X100 magnification) is restricted to villi at both timepoints. Probes were stained with 3,3'-diaminobenzidine (DAB), and tissues were counterstained with $50 \%$ hematoxylin. Scale bars indicate $50 \mu \mathrm{m}$. At d10, Lgr 5 probe densities in DF and EF chicks were calculated relative to crypt area (I), and PepT1 probe densities in DF and EF chicks were calculated relative to villus area (J). Values are means + SEM, and asterisks mark significant differences by $t$-test, $p<0.05$. 
compartments between Hatch and d10. Representative images from Hatch (Figure 3) and d10 DF chicks (Figure 4) demonstrate that at both timepoints, villi cells were all $\mathrm{FABP}^{+}$(Figures $3 \mathrm{~A}, \mathrm{E}$, 4A,F, dashed outlines), while some were also positive for PCNA (Figures 3B,F, 4B,G, asterisks), and crypt cells (Figures 3I,J, 4K,L) were either Sox $9^{+} / \mathrm{PCNA}^{-}$(arrows), Sox $9^{+} / \mathrm{PCNA}^{+}$ (arrowheads), Sox $9^{-} / \mathrm{PCNA}^{+}$(arrow outlines), or Sox9 ${ }^{-} / \mathrm{PCNA}^{-}$ (arrowhead outlines). Representative images from d10 EF chicks show a similar pattern of crypt and villi cell sub-type localization (Figures 4E,J,O).

Each of the two villus cell sub-types was quantified from the first $\mathrm{FABP}^{+}$villus cell, located within the crypt-villus border, up to the villus tip (Figure 5A). Results showed that in $\mathrm{EF}$ chicks, compared to DF chicks, $\mathrm{FABP}^{+} / \mathrm{PCNA}^{-}$cell counts were significantly higher at $\mathrm{d} 1, \mathrm{~d} 3, \mathrm{~d} 7$, and $\mathrm{d} 10(p<0.0001, p<0.0001$, $p=0.0027$; and $p=0.0011$, respectively), while $\mathrm{FABP}^{+} / \mathrm{PCNA}^{+}$ cell counts were significantly higher at $d 1(p<0.0001)$ and significantly lower at $\mathrm{d} 10(p=0.0011$; Figure 5A). The ratios between villus cell sub-types (Table 1) were significantly affected by the timing of first feeding at all timepoints: at $\mathrm{d} 1, \mathrm{FABP}^{+} /$ $\mathrm{PCNA}^{-}$cell ratios decreased and $\mathrm{FABP}^{+} / \mathrm{PCNA}^{+}$increased significantly $(p=0.0011)$, whereas at $\mathrm{d} 3, \mathrm{~d} 7$ and $\mathrm{d} 10, \mathrm{FABP}^{+} /$ $\mathrm{PCNA}^{-}$cell ratios decreased and $\mathrm{FABP}^{+} / \mathrm{PCNA}^{+}$increased significantly $(p<0.0001, p=0.0027$; and $p=0.0011$, respectively) in EF chicks, compared to DF chicks (Table 1). In the crypts, the four cell sub-types were quantified from crypt base to crypt-villus border (Figure 5B). EF chicks, compared to DF chicks, exhibited significantly increased Sox $9^{+} / \mathrm{PCNA}^{+}$and Sox $9^{-} /$ $\mathrm{PCNA}^{-}$cell counts at $\mathrm{d} 1$ ( $p<0.0001$ and $p=0.0012$, respectively), significantly decreased Sox $9^{+} / \mathrm{PCNA}^{-}$and increased Sox $9^{-} / \mathrm{PCNA}^{+}$ and Sox $9^{-} / \mathrm{PCNA}^{-}$cell counts at $\mathrm{d} 3(p=0.0001, p=0.0007$, $p=0.044$, respectively) and significantly increased Sox $9^{+} / \mathrm{PCNA}^{+}$
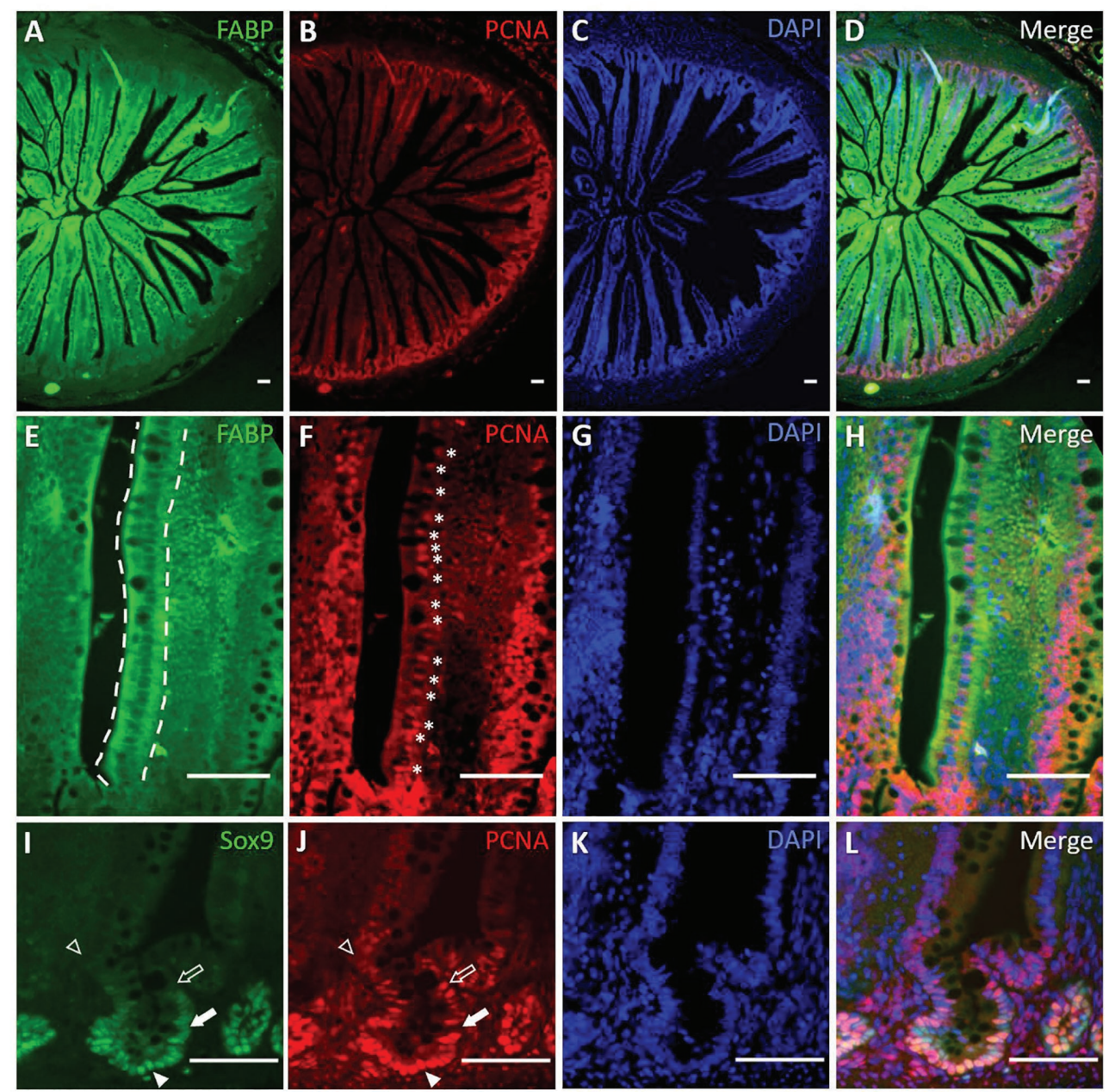

FIGURE 3 | Stem, progenitor, proliferating, and differentiated cells exhibit specific localization within villi and crypts at Hatch. Immunofluorescence (IF) of enterocyte marker fatty acid binding protein (FABP), proliferating cell nuclear antigen (PCNA), DAPI nuclear staining, and their merge at X100 magnification (A-D), and X400 magnification (E-H), and stem/progenitor cell marker SRY-Box Transcription Factor 9 (Sox9), PCNA, DAPI, and their merge (I-L) at Hatch. FABP expression was localized to all villus cells (E, dashed outlines). Proliferating cells were found along the villus (F, asterisks), overlapping FABP ${ }^{+}$cells. Sox9 expression was restricted to crypts (I). Arrows indicate Sox9 ${ }^{+} / \mathrm{PCNA}^{-}$cells, arrowheads indicate Sox9 $/ \mathrm{PCNA}^{+}$cells, arrow outlines indicate Sox9-/PCNA ${ }^{+}$cells, and arrowhead outlines indicate Sox9-/PCNA- cells (I,J). 
cell counts at $\mathrm{d} 7(p=0.0084)$. The ratio of each crypt cell sub-type was calculated as the fraction from total number of crypt cells (Table 1), and was found to be significantly affected by the timing of first feeding at d1, in which EF chicks exhibited significantly higher ratios of Sox9 $/ \mathrm{PCNA}^{-}$cells, compared to DF chicks $(p=0.015)$, and at $\mathrm{d} 3$, in which EF chicks exhibited significantly lower ratios of Sox $9^{+} / \mathrm{PCNA}^{-}$cells and significantly higher ratios of Sox $9^{-} / \mathrm{PCNA}^{+}$and Sox $9^{-} / \mathrm{PCNA}^{-}$cells, compared to DF chicks $(p<0.0001, p=0.0086$ and $p=0.0365$, respectively; Table 1). Lastly, goblet cells were quantified within crypts and villi at all timepoints by counting cells stained with Alcian blue and periodic acid Schiff (AB-PAS), which identifies their intracellular and secreted acidic and neutral mucins (Forstner et al., 1994; Uni et al., 2003a; Figure 6). Villi goblet cell counts were significantly lower at $\mathrm{d} 1(p=0.013)$ and significantly higher at $\mathrm{d} 7$ and $\mathrm{d} 10(p<0.0001)$ in EF chicks, compared to DF chicks (Figure $\mathbf{6 A}$ ). Their ratios, relative to the total number of villus cells, were accordingly lower at $\mathrm{d} 1(p<0.0001)$ and higher at $\mathrm{d} 7(p=0.0086)$ and $\mathrm{d} 10(p<0.0001)$ in EF chicks, compared to DF chicks (Table 2). Crypt goblet cell counts in EF chicks, compared to DF chicks, were also significantly lower at $\mathrm{d} 1(p<0.0001)$, yet were significantly higher at $\mathrm{d} 3, \mathrm{~d} 7$ and $\mathrm{d} 10(p=0.0159, p=0.0068$ and $p=0.0067$, respectively; Figure $6 \mathrm{~B}$ ). However, their ratios, relative to the total number of crypt cells, were affected by the timing of first feeding at $\mathrm{d} 3$ and $\mathrm{d} 10$ only, with significant increases in EF chicks, compared to DF chicks $(p=0.0011$ and $p=0.0013$, respectively; Table 2 ).

\section{DISCUSSION}

In this study, we have shown that early first feeding of chicks promoted early maturation of the small intestinal (SI) epithelium by: (1) increasing the quantities and proportions of progenitor and differentiated crypt cells and (2) increasing the quantities
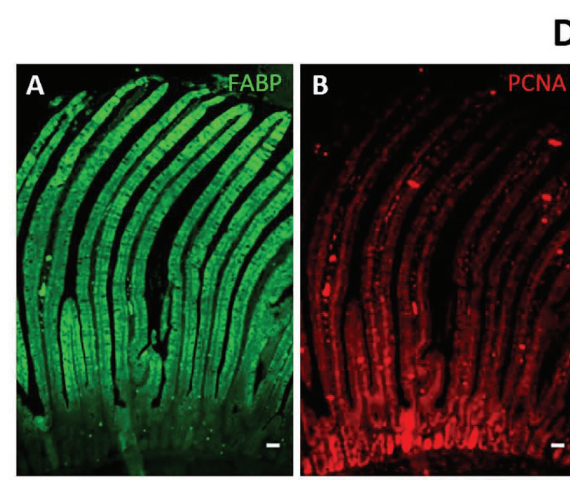

DF
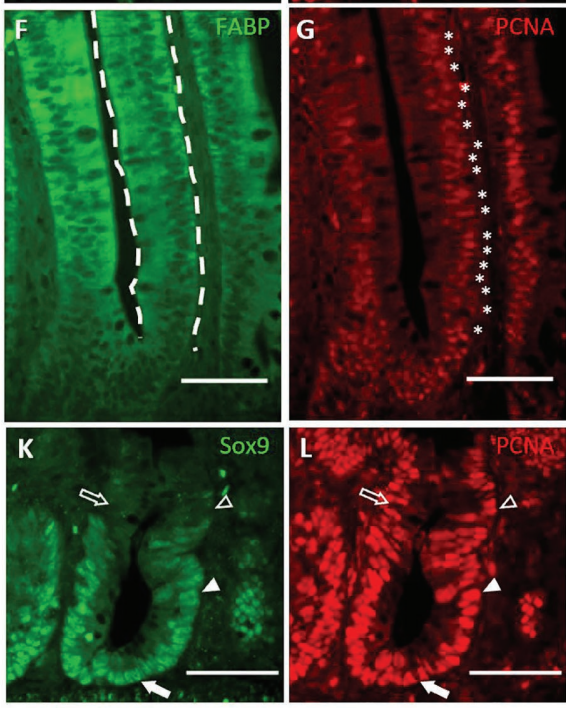
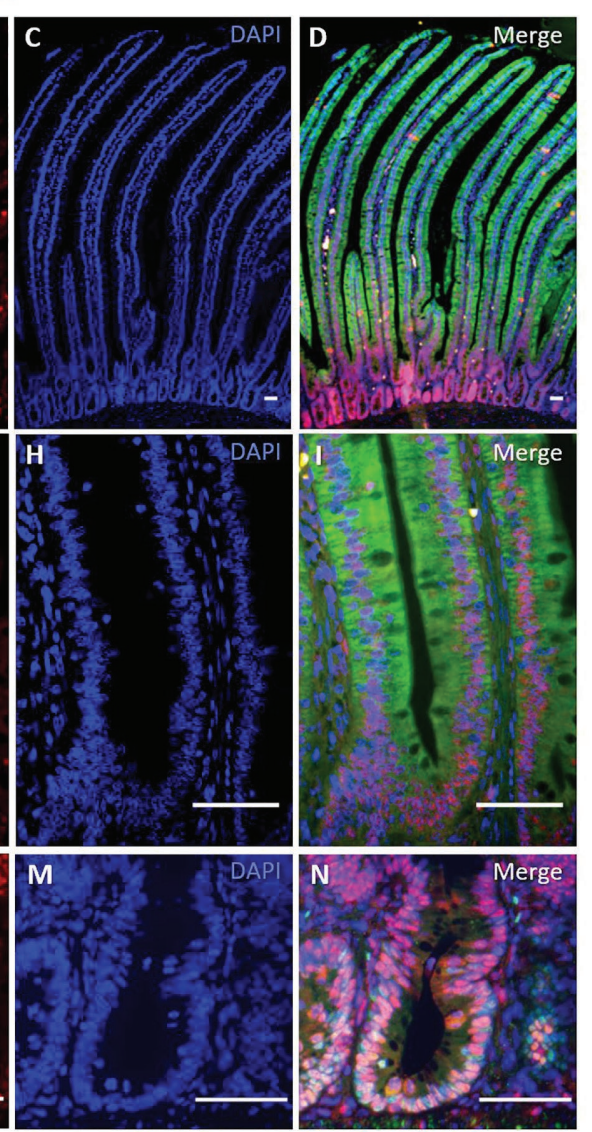
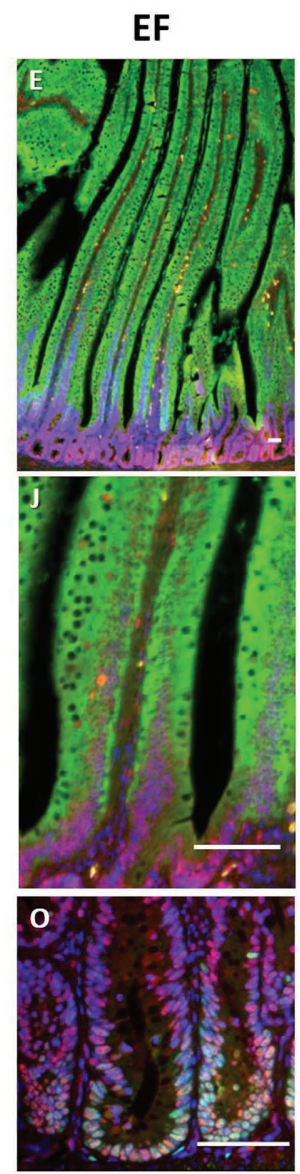

FIGURE 4 | Stem, progenitor, proliferating, and differentiated cells exhibit specific localization within villi and crypts at d10. IF of enterocyte marker FABP, PCNA, DAPI nuclear staining, and their merge at X100 magnification (A-D), and X400 magnification (F-I), and stem/progenitor cell marker Sox9, PCNA, DAPI, and their merge (K-N) in DF chicks at d10. Merged immunofluorescent images of the same markers in EF chicks at d10 are presented in the right, separate panel: FABP and PCNA at a magnification of X100 (E) and X400 (J); Sox9 and PCNA at X400 magnification (0). FABP expression was localized to all villus cells (F, dashed outlines). Proliferating cells were found along the villus (G, asterisks), colocalizing with FABP ${ }^{+}$cells. Sox9 expression was restricted to crypts (K). Arrows indicate Sox $9^{+} /$ $\mathrm{PCNA}^{-}$cells, arrowheads indicate Sox9 ${ }^{+} / \mathrm{PCNA}^{+}$cells, arrow outlines indicate Sox9-/PCNA ${ }^{+}$cells, and arrowhead outlines indicate Sox9-/PCNA- cells (K,L). 


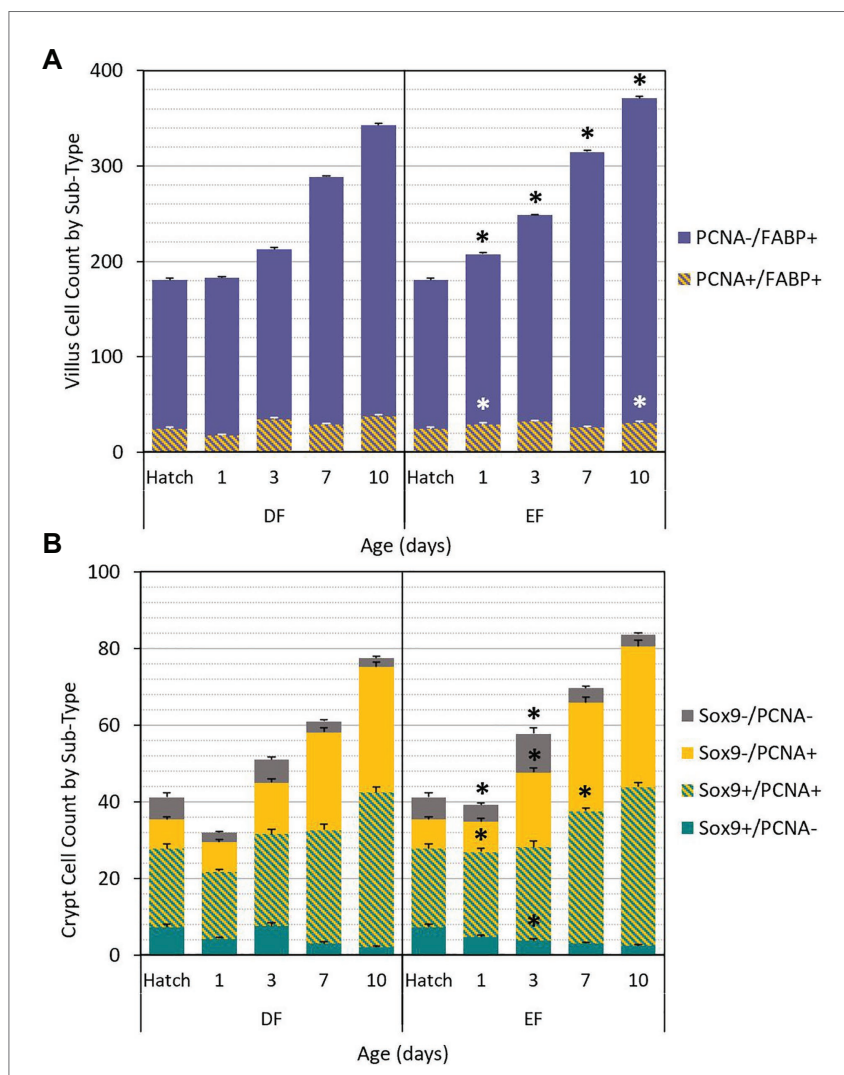

FIGURE 5 | Villus and crypt cell sub-type counts are affected by the timing of first feeding. (A) Villus cell sub-type counts by IF between Hatch and d10 in DF chicks (left) and EF chicks (right). Cells were either FABP+/PCNA- (purple bars), or $\mathrm{FABP}^{+} / \mathrm{PCNA}^{+}$(lined bars). (B) Crypt cell sub-type counts by IF between Hatch and d10 in DF chicks (left) and EF chicks (right). Cells were either Sox9+/ $\mathrm{PCNA}^{-}$(teal bars), Sox9+/PCNA+ (lined bars), Sox9-/PCNA ${ }^{+}$(yellow bars), or Sox9-/PCNA ${ }^{-}$(gray bars). Values are means + SEM, asterisks mark significant differences between DF and EF at each age by $t$-test, $p<0.05$.

and proportions of mature enterocytes in the villi. Our results show that the timing of first feeding of chicks alters SI morphology and functionality during the initial 10 days posthatch through changes in the distribution of stem $\left(\mathrm{Sox}^{+} /\right.$ $\left.\mathrm{PCNA}^{-}\right)$, progenitor $\left(\right.$Sox $\left.9^{+} / \mathrm{PCNA}^{+}\right)$, proliferating $\left(\mathrm{Sox}^{-} / \mathrm{PCNA}^{+}\right)$ and differentiated $\left(\mathrm{Sox} 9^{-} / \mathrm{PCNA}^{-}\right)$cells in the crypts, and proliferating $\left(\mathrm{PCNA}^{+} / \mathrm{FABP}^{+}\right)$, and differentiated cells $\left(\mathrm{PCNA}^{-} /\right.$ $\mathrm{FABP}^{+}$and goblet cells) in the villi.

During the initial 10 days post-hatch, we identified $\operatorname{Lgr} 5^{+}$and Sox $9^{+}$stem cells that were restricted to crypts, and PepT $1^{+}$and $\mathrm{FABP}^{+}$enterocytes that populated the villi. This distribution pattern is similar to that of the mouse and human SI epithelium (Barker et al., 2007; Gehart and Clevers, 2019). Sox9 is a Wnt target transcription factor, which is expressed in high levels by non-dividing stem cells, and is associated in low levels with progenitor cells (Bastide et al., 2007; Gracz et al., 2010; Bankaitis et al., 2018). In light of this, we divided crypt cells into four sub-types and characterized Sox $9^{+} / \mathrm{PCNA}^{-}$cells as non-dividing crypt-base stem cells, Sox $9^{+} / \mathrm{PCNA}^{+}$cells as progenitor cells, Sox $9^{-} / \mathrm{PCNA}^{+}$cells as proliferating cells and Sox ${ }^{-} / \mathrm{PCNA}^{-}$cells as differentiated, non-enteroendocrine cells.
Unlike humans and mice, in which proliferating cells are restricted to the crypt zone, proliferation marker PCNA in chicks was expressed both in crypt cells and along villi, within cells co-expressing FABP. The presence of proliferating cells within the SI villus has been previously documented in chicken of varying ages (Uni et al., 1998; Zhang et al., 2014), as well as in numerous other species, ranging from mammals (Verdile et al., 2019) to reptiles (Helmstetter et al., 2009; Borges et al., 2018), amphibians (Ikuzawa et al., 2006), and fish (Sklan et al., 2004; LØkka et al., 2013; Verdile et al., 2020). Species-dependent changes in feeding behavior and digestive physiology have been found to alter the quantities of villus proliferating cells, thus reflecting the regenerative capacity of the SI epithelium. For example, in pigs, $\mathrm{PCNA}^{+}$cell quantities increased from birth during the suckling period and decreased as a result of weaning stress (Verdile et al., 2019). Furthermore, prolonged fasting and refeeding, which naturally occur in snakes, frogs, and fish, correlated with respective decreases and increases in $\mathrm{PCNA}^{+}$ intestinal epithelial cells (Helmstetter et al., 2009; Takahashi et al., 2014; Tamaoki et al., 2016). Chicken and other precocial birds exhibit dramatic changes in intestinal morphology and functionality during the peri-hatch period, in which their digestive tract undergoes a transition from embryonic, egg-based nutrition, to external nutrition (Uni et al., 1999, 2003b; Gilbert et al., 2007; Ding et al., 2011; Miska et al., 2014). Numerous studies have shown that the timing of first feeding, which may occur 24-72 $\mathrm{h}$ post-hatch in current poultry production practices, is critical for shaping the SI mucosa during the initial post-hatch period (Noy and Sklan, 1999; Bigot et al., 2003; Uni et al., 2003a).

We therefore sought to examine the quantity and spatial distribution of stem, progenitor, proliferating, and differentiated cells within the SI epithelium, in order to piece the puzzle of how specialized cell sub-types govern SI morphology and function, under the effects of EF, compared to $24 \mathrm{~h} \mathrm{DF}$, during several timepoints throughout the first $10 \mathrm{~d}$ post-hatch. These timepoints will be further discussed.

\section{Hatch to d1}

The first $24 \mathrm{~h}$ post-hatch is a period in which the quantities of egg-yolk nutrients diminish, and chicks become reliant on external feed for their development (Noy and Sklan, 1998; Yadgary et al., 2010). During this period, SI crypt development begins, and villi, that develop prior to hatch, expand and elongate (Uni et al., 2000, 2003b; Shyer et al., 2013).

Our work showed that lack of feed during this period resulted in stunted villus growth and decreased crypt cell counts. In contrast, feeding upon hatch maintained crypt cell counts and increased villi cell counts. This increase was not reflected in villi heights due to small villus cell dimensions during this $24 \mathrm{~h}$ period (Uni et al., 1998). The villus-crypt cell ratio was significantly higher at d1 than at Hatch, in both DF (un-fed) chicks and EF (fed) chicks. This indicates that during the first $24 \mathrm{~h}$ posthatch, villi develop faster than crypts, but maintain a $\approx 5.5$ ratio of villus cells per crypt cell, which was not affected by feeding. The timing of first feeding did not affect the ratios of stem, progenitor, and proliferating cells in the crypts. However, DF chicks exhibited decreased crypt differentiated cell ratios, indicating 
TABLE 1 | Villus and crypt cell sub-type ratios between Hatch and d10 in delayed feeding (DF) and early feeding (EF) chicks.

\begin{tabular}{|c|c|c|c|c|c|c|c|}
\hline \multirow[t]{2}{*}{ Age (days) } & \multirow[t]{2}{*}{ EF/DF } & \multicolumn{2}{|c|}{ Villus cell ratios (\%) } & \multicolumn{4}{|c|}{ Crypts cell ratios (\%) } \\
\hline & & $\mathrm{FABP}^{+} / \mathrm{PCNA}^{+}$ & $\mathrm{FABP}^{+} / \mathrm{PCNA}^{-}$ & Sox $9^{+} / \mathrm{PCNA}^{-}$ & Sox9 $^{+} / \mathrm{PCNA}^{+}$ & Sox9-/PCNA $^{+}$ & Sox9-/PCNA \\
\hline Hatch & - & $13.4 \pm 1.1$ & $86.6 \pm 1.1$ & $17.8 \pm 2$ & $49.7 \pm 2.6$ & $19 \pm 1.8$ & $13.5 \pm 2.4$ \\
\hline \multirow{2}{*}{ D1 } & DF & $9.3 \pm 0.8$ & $90.7 \pm 0.8$ & $13.1 \pm 1.3$ & $55.6 \pm 2$ & $23.8 \pm 1.7$ & $7.5 \pm 0.7$ \\
\hline & EF & $13.9 \pm 1 *$ & $86.1 \pm 1 *$ & $12.3 \pm 1.4$ & $57.3 \pm 2.1$ & $19.2 \pm 1.8$ & $11.2 \pm 1.3 *$ \\
\hline \multirow{2}{*}{ D3 } & DF & $16.2 \pm 0.9$ & $83.8 \pm 0.9$ & $15 \pm 1.7$ & $46.9 \pm 2$ & $26.1 \pm 1.7$ & $12 \pm 1.3$ \\
\hline & EF & $12.9 \pm 0.4 *$ & $87.1 \pm 0.4^{*}$ & $6.5 \pm 1.9 *$ & $42.6 \pm 2.7$ & $33.2 \pm 1.9 *$ & $17.7 \pm 2.9 *$ \\
\hline \multirow{2}{*}{ D7 } & DF & $10.1 \pm 0.4$ & $89.9 \pm 0.4$ & $4.7 \pm 0.8$ & $48.3 \pm 2.2$ & $42.1 \pm 1.9$ & $4.9 \pm 0.9$ \\
\hline & EF & $8.1 \pm 0.5^{*}$ & $91.9 \pm 0.5^{*}$ & $4.4 \pm 0.4$ & $49.9 \pm 1.5$ & $40.4 \pm 1.7$ & $5.5 \pm 0.7$ \\
\hline \multirow{2}{*}{ D10 } & DF & $11 \pm 0.5$ & $89 \pm 0.5$ & $2.5 \pm 0.5$ & $52.1 \pm 1.5$ & $42.4 \pm 1.3$ & $3 \pm 0.6$ \\
\hline & EF & $8.2 \pm 0.6 *$ & $91.8 \pm 0.6 *$ & $2.8 \pm 0.4$ & $49.9 \pm 1.4$ & $43.5 \pm 1.4$ & $3.8 \pm 0.6$ \\
\hline
\end{tabular}

Ratios of cell sub-types, relative to the total number villus/crypt cells. Values are means \pm SEM, asterisks, and bold lettering mark significant differences between DF chicks and EF chicks at each age by $t$-test, $p<0.05$.

reduced functionality as a result of absence of feed during the initial $24 \mathrm{~h}$. In the villi, ratios of proliferating cells were reduced in comparison to EF chicks and chicks at Hatch. Villi of EF chicks were composed of a higher number of FABP+ enterocytes and their goblet cell ratios were reduced, compared to DF chicks and chicks at Hatch. We therefore hypothesize that the halted development of villi of DF chicks may be attributed to reduced proliferation within the villi, and that feeding upon hatch maintained villus proliferation, resulting in a larger population of enterocytes, rather than goblet cells. Taken together, during the first $24 \mathrm{~h}$ post-hatch, external feed promotes the initial expansion of the digestive and absorptive surface area of the SI epithelium by supporting villus cell proliferation.

\section{d3}

Between $\mathrm{d} 1$ and $\mathrm{d} 3$, the SI epithelium expanded in both groups, yet early feeding further promoted villus and crypt hyperplasia. EF chicks exhibited higher villi and crypt cell counts, compared to DF chicks. The villus-crypt cell ratio did not differ between groups, but decreased to $\approx 4$. This indicates a shift at $\mathrm{d} 3$ toward a faster rate of crypt expansion, compared to villus elongation, and further emphasizes that this ratio is independent of the timing of first feeding. However, EF, compared to DF, shifted the ratios between crypt cell sub-types toward a decrease in crypt-base stem cell ratios, and increases in proliferating and differentiated cell ratios. Crypt cell sub-type ratios of DF chicks resembled those of chicks at $\mathrm{d} 1$, while those of EF chicks assumed a pattern more similar to later ages, which will be further discussed. In the villi, EF chicks exhibited higher counts and ratios of non-proliferating, FABP+ enterocytes, compared to DF chicks. Though crypt goblet cell counts and ratios were higher in EF chicks compared to DF chicks, their counts and ratios within the villi did not differ between EF chicks and DF chicks. Hence, EF promoted the differentiation of crypt cells into enterocytes, for further expansion of the digestive and absorptive area of the villi.

\section{d7 and d10}

The SI mucosa of chicks was previously reported to reach morphological and functional maturity at days 7-10 (Uni et al., 1998, 1999). Accordingly, villus-crypt cell ratios stabilized to a ratio of $\approx 4.8$ during these ages. The SI epithelium continuously expanded at $\mathrm{d} 7$ and $\mathrm{d} 10$, and crypt and villi cell counts remained higher in EF chicks, compared to DF chicks. This indicates that feeding upon Hatch, compared to 24 h-delayed feeding, elicits long-lasting hyperplasia of the SI epithelium.

At $\mathrm{d} 7$ and d10, crypts maintained a steady balance between Sox9+ stem cells and proliferating PCNA+ crypt cells, with lower stem cell ratios and higher proliferating cell ratios, in comparison to earlier timepoints. There were no differences in stem cell quantities and ratios between groups at these timepoints, in accordance with the similar expression patterns of Lgr5 mRNA in both groups at d10. Though several studies have found Lgr5+ crypt stem cells to co-express Sox9 (Gracz et al., 2010; Furuyama et al., 2011), a study by Roche et al. (2015) showed that varying levels of Lgr5 and Sox9 expression mark functionally different of crypt stem cells. Therefore, we conclude that by d10, the crypt stem cell population reaches a steady state in the chick SI epithelium and is no longer affected by the timing of first feeding.

In the villi at $\mathrm{d} 7$ and $\mathrm{d} 10$, the ratios of proliferating cells decreased in EF chicks, compared to DF chicks, and the quantities and ratios of mature enterocytes increased accordingly. This indicates that the increased digestive and absorptive surface of $\mathrm{SI}$, as a result of EF, compared to DF, was maintained after 10 days. This was also evident by increased expression of enterocyte marker PepT1 in villi of EF chicks, compared to DF chicks, at d10. As for goblet cells, their ratios were higher in EF chicks compared to DF chicks at $\mathrm{d} 7$ and $\mathrm{d} 10$. This could be a result of the higher ratio of crypt goblet cells in EF chicks at d3, since crypt goblet cells give rise to the villus goblet cell population in a time-dependent manner (Paulus et al., 1993).

Taken together, early feeding, compared to 24 h-delayed feeding, increased the amounts of villus enterocytes and goblet cells at $\mathrm{d} 7$ and $\mathrm{d} 10$, thus improving the SI functionality upon its maturation. These results demonstrate how a $24 \mathrm{~h}$ difference in the timing of first feeding elicits ongoing effects on the SI epithelium, which improve its functionality during the critical first 10 days posthatch. Figure 7 summarizes the major findings in this study.

Our results provide further insights into the effects of the timing of first feeding on the cell sub-type quantities and distribution in SI epithelium, which generate and maintain SI morphology and functionality. Increased proliferation and 


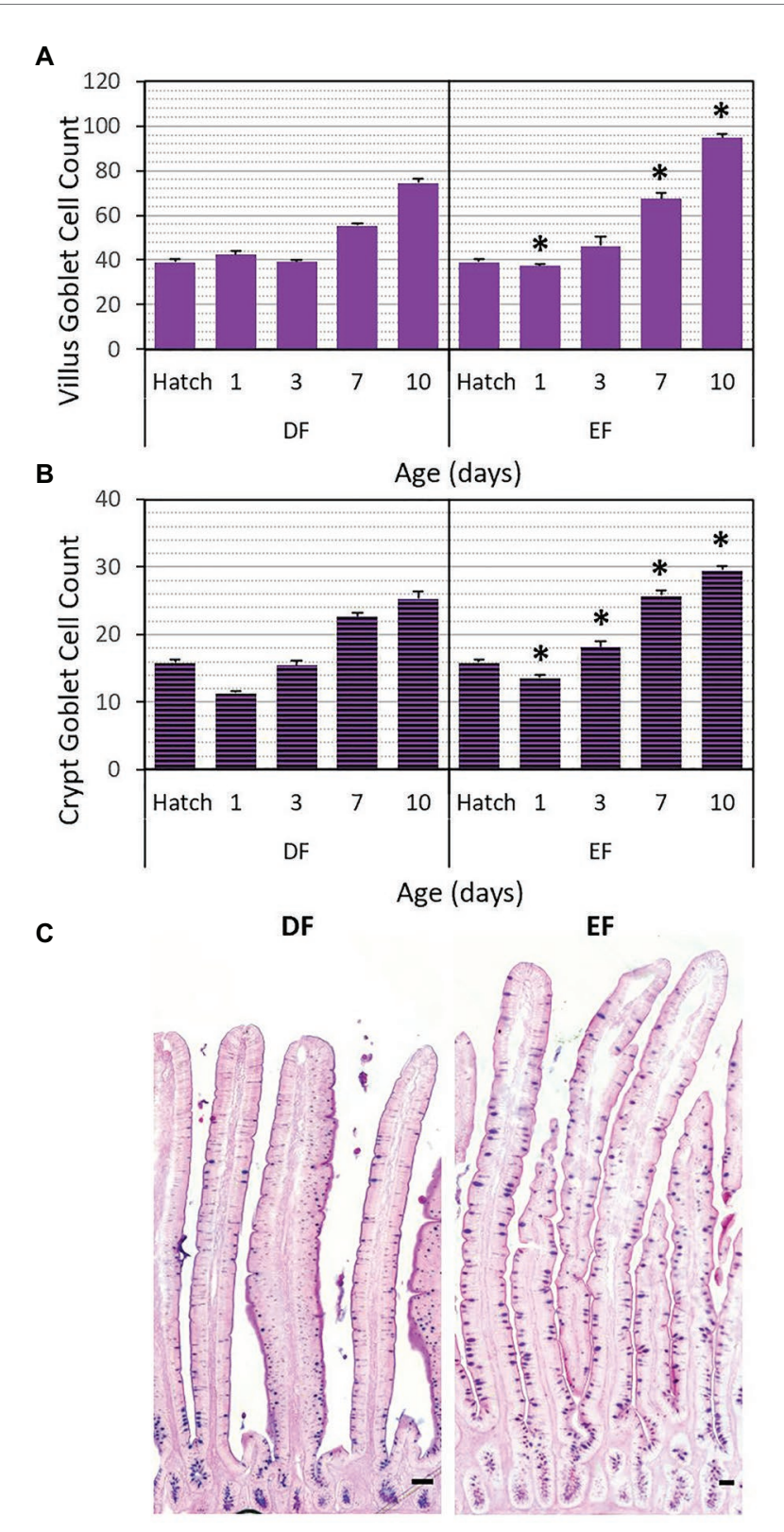

FIGURE 6 | Villus and crypt goblet cell counts between Hatch and d10 are affected by the timing of first feeding. Goblet cells were quantified by counting Alcian blue-periodic acid Schiff (AB-PAS) mucin staining in villi (A) and crypts (B) between Hatch and d10 in DF and EF chicks. Values are means + SEM, and asterisks mark significant differences between DF and EF chicks for each age by $t$-test, $p<0.05$. (C) Representative images of AB-PAS staining at $\mathrm{d} 10$ in DF and EF chicks. Scale bars indicate $50 \mu \mathrm{m}$.

differentiation shifted the SI epithelium into early maturation and enhanced functionality throughout the critical 10 days post-hatch period. These effects may be attributed to the contribution of specific nutrients to SI epithelial development, as indications for epigenetic programming of intestinal stem cell differentiation by dietary methionine have been reported (Obata et al., 2018). Moreover, the mechanical stimulation of the SI mucosa by luminal contents may also play a critical
TABLE 2 | Villus and goblet cell ratios between Hatch and d10 in DF and EF chicks.

Age (days) EF/DF Villus goblet cell ratio (\%) Crypts goblet cell ratio (\%)

\begin{tabular}{llcc}
\hline Hatch & - & $21.5 \pm 0.7$ & $41.7 \pm 1.2$ \\
D1 & DF & $23.4 \pm 0.9$ & $31.9 \pm 1$ \\
& EF & $\mathbf{1 8 . 1} \pm \mathbf{0 . 4 *}$ & $33 \pm 1$ \\
D3 & DF & $18.6 \pm 0.4$ & $30.9 \pm 1.3$ \\
& EF & $18 \pm 1.2$ & $\mathbf{3 7 . 4} \pm \mathbf{1 . 3} *$ \\
D7 & DF & $19.2 \pm 0.4$ & $42.5 \pm 1.2$ \\
& EF & $\mathbf{2 1 . 5} \pm \mathbf{0 . 8 *}$ & $40 \pm 1.1$ \\
D10 & DF & $21.8 \pm 0.6$ & $41.7 \pm 1.4$ \\
& EF & $\mathbf{2 5 . 5} \pm \mathbf{0 . 4 *}$ & $\mathbf{4 6 . 7} \pm \mathbf{0 . 9} *$ \\
\hline
\end{tabular}

Ratios of villus and crypt goblet cells, relative to the total number villus/crypt cells. Values are means \pm SEM, asterisks, and bold lettering mark significant differences between DF chicks and EF chicks at each age by t-test, $p<0.05$.

role in SI epithelial maturation. Studies of parenteral nutrition in humans and mice reported cellular atrophy and altered differentiation patterns in the SI epithelium in response to absence of mechanoluminal stimulation (Kovalenko and Basson, 2012; Wieck et al., 2017). In chicken, decreased villus heights due to fasting were recovered by enteral feeding, but not parenteral nutrition or non-nutritional luminal stimulation (Tarachai and Yamauchi, 2000). However, non-nutritional luminal stimulation improved weight gain in chicks susceptible to delayed feeding (Noy and Sklan, 1999). This demonstrates the contribution of luminal stimulation to the development and functionality of SI mucosa. Additionally, a growing body of evidence suggests that early feeding strategies can modulate the chick SI microbiota (Rubio, 2019). Since the gut microbiota affects SI structure and function (Dobrowolski et al., 2019), the timing of microbial introduction by external feed may also play a critical role in shaping the SI epithelium.

Although previous studies have demonstrated the effect of the timing of first feeding of chicks on growth, nutrient utilization, metabolic pathways, gut integrity, and immunity (Bigot et al., 2003; Bar Shira et al., 2005; de Jong et al., 2017; Hicks et al., 2019; Payne et al., 2019; Proszkowiec-weglarz et al., 2020), no study has shown the effects on crypt and villi epithelial cell sub-types, involved in cellular turnover and intestinal functionality. Our study is the first to show the effect of the timing of first feeding on the quantities and proportions of stem, progenitor, proliferating, and differentiated SI epithelial cells, through immunofluorescence and histochemical of specific cell sub-type markers.

The question whether the timing of first feeding elicits longterm effects on SI epithelial cell sub-type dynamics should be investigated in future studies. Mainly, whether early feeding promotes the differentiation of specific progenitor cells into particular epithelial cell sub-types associated with intestinal functionality, integrity, and immunity.

In conclusion, in chicks, early feeding influenced the dynamics between stem, progenitor, proliferating, and differentiated cells in the SI epithelium. Feeding upon hatch, as opposed to 24 h-delayed feeding (a routine procedure worldwide in the poultry production), elicited hyperplasia of progenitor and differentiated cells within the crypts and villi over the course of 10 days. This resulted in deeper crypts, higher villi, and a 


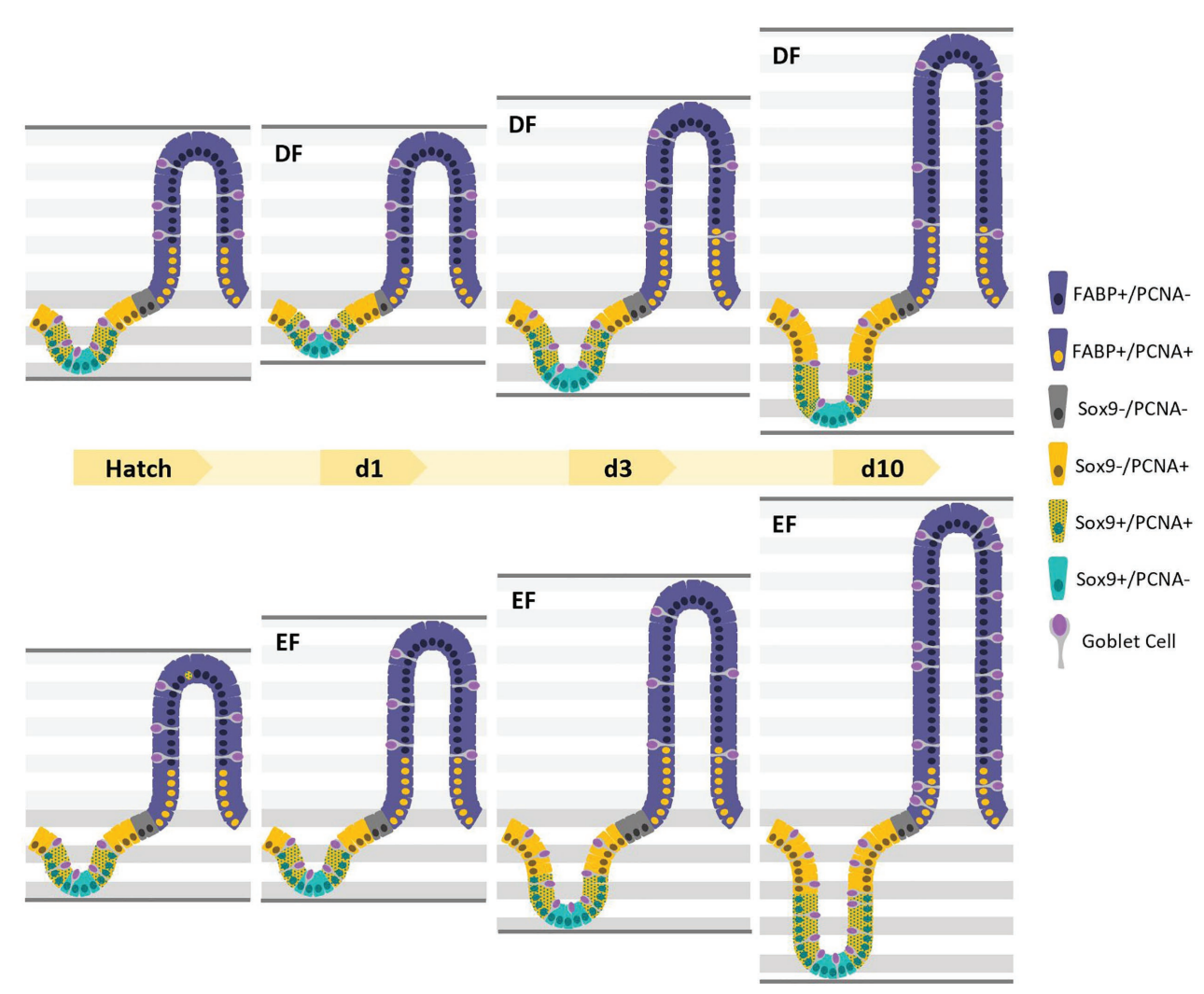

FIGURE 7 | Timing of first feeding of chicks shapes the SI epithelium throughout development by altering the quantities and ratios of crypt and villus cell sub-types. Graphical representation of the major findings in this study. Villus cells were either positive for both $\mathrm{FABP}^{+}$and $\mathrm{PCNA}^{+}$or FABP $\mathrm{FPCNA}^{-}$, and crypt cells were either positive for Sox9 and $\mathrm{PCNA}^{-}$, Sox9 ${ }^{+} / \mathrm{PCNA}^{+}$, Sox9-/PCNA ${ }^{+}$, or Sox9 $-/ \mathrm{PCNA}^{-}$. Goblet cells were intermittently scattered throughout the crypt and villus epithelium. The effects of EF, compared to DF first feeding are represented by the total amount of villus and crypt cells and the quantities and ratios of each villus/crypt cell type, at $\mathrm{d} 1, \mathrm{~d} 3$, and $\mathrm{d} 10$ (in which results resembled those of $\mathrm{d} 7 \mathrm{in}$ both groups).

consequential expansion of the functional absorptive, digestive, and secretive surface area of the SI.

\section{DATA AVAILABILITY STATEMENT}

The raw data supporting the conclusions of this article will be made available by the authors, without undue reservation.

\section{ETHICS STATEMENT}

The animal study was reviewed and approved by IACUC:AG-1715355-2.

\section{REFERENCES}

Bankaitis, E. D., Ha, A., Kuo, C. J., and Magness, S. T. (2018). Reserve stem cells in intestinal homeostasis and injury. Gastroenterology 155, 1348-1361. doi: $10.1053 /$ j.gastro.2018.08.016

Bar Shira, E., and Friedman, A. (2018). Innate immune functions of avian intestinal epithelial cells: response to bacterial stimuli and localization of responding cells in the developing avian digestive tract. PLoS One 13:e200393. doi: 10.1371 /journal.pone.0200393

\section{AUTHOR CONTRIBUTIONS}

NR: PhD student, experimental design, execution, data anlysis, and manuscript writing. TM-Z and JD: experimental methodologies. $\mathrm{ZU}$ : supervision, funding, and manuscript review. All authors contributed to the article and approved the submitted version.

\section{FUNDING}

This research was supported by Research Grant No. US-507418CR from the United States-Israel Binational Agricultural Research and Development Fund (BARD).

Bar Shira, E., Sklan, D., and Friedman, A. (2005). Impaired immune responses in broiler hatchling hindgut following delayed access to feed. Vet. Immunol. Immunopathol. 105, 33-45. doi: 10.1016/j.vetimm.2004.12.011

Barker, N., van Es, J. H., Kuipers, J., Kujala, P., van den Born, M., Cozijnsen, M., et al. (2007). Identification of stem cells in small intestine and colon by marker gene Lgr5. Nature 449, 1003-1008. doi: 10.1038/nature06196

Bastide, P., Darido, C., Pannequin, J., Kist, R., Robine, S., Marty-Double, C., et al. (2007). Sox9 regulates cell proliferation and is required for paneth cell differentiation in the intestinal epithelium. J. Cell Biol. 178, 635-648. doi: 10.1083/jcb.200704152 
Bigot, K., Mignon-Grasteau, S., Picard, M., and Tesseraud, S. (2003). Effects of delayed feed intake on body, intestine, and muscle development in neonate broilers. Poult. Sci. 82, 781-788. doi: 10.1093/ps/82.5.781

Blache, P., van de Wetering, M., Duluc, I., Domon, C., Berta, P., Freund, J. N., et al. (2004). SOX9 is an intestine crypt transcription factor, is regulated by the Wnt pathway, and represses the CDX2 and MUC2 genes. J. Cell Biol. 166, 37-47. doi: 10.1083/jcb.200311021

Borges, R. M., Pressinotti, L. N., Marcus, F. A., Iunes, R. S., Aleixo, V. M., Portela, T. C. L., et al. (2018). Histological organization of intestinal villi in the crocodilian Caiman yacare (Daudin, 1802) during dietary lipid absorption. Zoomorphology 137, 419-432. doi: 10.1007/s00435-018-0401-3

Carulli, A. J., Samuelson, L. C., and Schnell, S. (2014). Unraveling intestinal stem cell behavior with models of crypt dynamics. Integr. Biol. 6, 243-257. doi: $10.1039 / \mathrm{c} 3 \mathrm{ib} 40163 \mathrm{~d}$

de Jong, I. C., van Riel, J., Bracke, M. B. M., and van den Brand, H. (2017). A 'meta-analysis' of effects of post-hatch food and water deprivation on development, performance and welfare of chickens. PLoS One 12:e0189350. doi: 10.1371/journal.pone.0189350

Ding, B. A., Pirone, A., Lenzi, C., Xiaoming, N., Baglini, A., and Romboli, I. (2011). Histochemical features of the muscovy duck small intestine during development. Tissue Cell 43, 190-195. doi: 10.1016/j.tice.2011.03.001

Dobrowolski, P., Tomaszewska, E., Klebaniuk, R., Tomczyk-Warunek, A., Szymańczyk, S., Donaldson, J., et al. (2019). Structural changes in the small intestine of female turkeys receiving a probiotic preparation are dose and region dependent. Animal 13, 2773-2781. doi: 10.1017/ S1751731119001149

Fei, Y. J., Sugawara, M., Liu, J. C., Li, H. W., Ganapathy, V., Ganapathy, M. E., et al. (2000). cDNA structure, genomic organization, and promoter analysis of the mouse intestinal peptide transporter PEPT1. Biochim. Biophys. Acta 1492, 145-154. doi: 10.1016/s0167-4781(00)00101-9

Forstner, J. F., Forstner, G. G., Leonard, P., and Johnson, R. (1994). “Gastrointestinal mucus" in Physiology of the gastrointestinal tract. 3rd Edn. eds. L. Royse, M. Conner, J. Meyer and T. Broderick (New York: Raven Press), 1255-1283.

Furuyama, K., Kawaguchi, Y., Akiyama, H., Horiguchi, M., Kodama, S., Kuhara, T., et al. (2011). Continuous cell supply from a Sox9-expressing progenitor zone in adult liver, exocrine pancreas and intestine. Nat. Genet. 43, 34-41. doi: $10.1038 / \mathrm{ng} .722$

Gehart, H., and Clevers, H. (2019). Tales from the crypt: new insights into intestinal stem cells. Nat. Rev. Gastroenterol. Hepatol. 16, 19-34. doi: 10.1038/ s41575-018-0081-y

Geyra, A., Uni, Z., Gal-Garber, O., Guy, D., and Sklan, D. (2002). Starving affects CDX gene expression during small intestinal development in the chick. J. Nutr. 132, 911-917. doi: 10.1093/jn/132.5.911

Geyra, A., Uni, Z., and Sklan, D. (2001). The effect of fasting at different ages on growth and tissue dynamics in the small intestine of the young chick. Br. J. Nutr. 86, 53-61. doi: 10.1079/BJN2001368

Gilbert, E. R., Li, H., Emmerson, D. A., Webb, K. E. Jr., and Wong, E. A. (2007). Developmental regulation of nutrient transporter and enzyme mRNA abundance in the small intestine of broilers. Poult. Sci. 86, 1739-1753. doi: $10.1093 / \mathrm{ps} / 86.8 .1739$

Gracz, A. D., Ramalingam, S., and Magness, S. T. (2010). Sox9 expression marks a subset of CD24-expressing small intestine epithelial stem cells that form organoids in vitro. Am. J. Physiol. Gastrointest. Liver Physiol. 298, 590-600. doi: 10.1152/ajpgi.00470.2009

Halpern, K. B., Massalha, H., Zwick, R. K., Moor, A. E., Castillo-Azofeifa, D., Rozenberg, M., et al. (2020). Lgr5+ telocytes are a signaling source at the intestinal villus tip. Nat. Commun. 11, 3-14. doi: 10.1038/s41467-020-15714-x

Helmstetter, C., Pope, R. K., T'Flachebba, M., Secor, S. M., and Lignot, J. H. (2009). The effects of feeding on cell morphology and proliferation of the gastrointestinal tract of juvenile burmese pythons (Python molurus). Can. J. Zool. 87, 1255-1267. doi: 10.1139/Z09-110

Hicks, J. A., Porter, T. E., Sunny, N. E., and Liu, H. C. (2019). Delayed feeding alters transcriptional and post-transcriptional regulation of hepatic metabolic pathways in peri-hatch broiler chicks. Genes 10:272. doi: 10.3390/genes10040272

Ikuzawa, M., Shimizu, K., Yasumasu, S., Iuchi, I., Shi, Y. B., and Ishizuya-Oka, A. (2006). Thyroid hormone-induced expression of a bzip-containing transcription factor activates epithelial cell proliferation during xenopus larval-to-adult intestinal remodeling. Dev. Genes Evol. 216, 109-118. doi: 10.1007/ s00427-005-0037-4
Kovalenko, P. L., and Basson, M. D. (2012). Changes in morphology and function in small intestinal mucosa after roux-en-Y surgery in a rat model. J. Surg. Res. 177, 63-69. doi: 10.1016/j.jss.2012.03.011

Kubben, F. J., Peeters-Haesevoets, A., Engels, L. G., Baeten, C. G., Schutte, B., Arends, J. W., et al. (1994). Proliferating cell nuclear antigen (PCNA): a new marker to study human colonic cell proliferation. Gut 35, 530-535. doi: 10.1136/gut.35.4.530

LØkka, G., Austb, L., Falk, K., Bjerkås, I., and Koppang, E. O. (2013). Intestinal morphology of the wild Atlantic salmon (Salmo Salar). J. Morphol. 274, 859-876. doi: 10.1002/jmor.20142

Miska, K. B., Fetterer, R. H., and Wong, E. A. (2014). The mRNA expression of amino acid transporters, aminopeptidase $\mathrm{N}$, and the di- and tri-peptide transporter PepT1 in the embryo of the domesticated chicken (Gallus gallus) shows developmental regulation. Poult. Sci. 93, 2262-2270. doi: 10.3382/ ps.2014-03983

Moor, A. E., Harnik, Y., Ben-Moshe, S., Massasa, E. E., Rozenberg, M., Eilam, R. et al. (2018). Spatial reconstruction of single enterocytes uncovers broad zonation along the intestinal villus axis. Cell 175, 1156-1167. doi: 10.1016/j. cell.2018.08.063

Noy, Y., and Sklan, D. (1998). Yolk utilization in the newly hatched poult. Br. Poult. Sci. 39, 446-451. doi: 10.1080/00071669889042

Noy, Y., and Sklan, D. (1999). Different types of early feeding and performance in chicks and poults. J. Appl. Poult. Res. 8, 16-24. doi: 10.1093/japr/8.1.16

Obata, F., Tsuda-Sakurai, K., Yamazaki, T., Nishio, R., Nishimura, K., Kimura, M., et al. (2018). Nutritional control of stem cell division through S-adenosylmethionine in drosophila intestine. Dev. Cell 44, 741-775. doi: 10.1016/j.devcel.2018.02.017

Paulus, U., Loeffler, M., Zeidler, J., Owen, G., and Potten, C. S. (1993). The differentiation and lineage development of goblet cells in the murine small intestinal crypt: experimental and modelling studies. J. Cell Sci. 106, 473-483.

Payne, J. A., Proszkowiec-Weglarz, M., and Ellestad, L. E. (2019). Delayed access to feed alters expression of genes associated with carbohydrate and amino acid utilization in newly hatched broiler chicks. Am. J. Phys. Regul. Integr. Comp. Phys. 317, R864-R878. doi: 10.1152/ajpregu.00117.2019

Potten, C. S., and Loeffler, M. (1990). Stem cells: attributes, cycles, spirals, pitfalls and uncertainties. Lessons for and from the crypt. Development 110, 1001-1020.

Proszkowiec-weglarz, M., Schreier, L. L., Kahl, S., Miska, K. B., Russell, B., and Elsasser, T. H. (2020). Effect of delayed feeding post-hatch on expression of tight junction- and gut barrier-related genes in small intestine of broiler chickens during neonatal development. Poult. Sci. 99, 4714-4729. doi: 10.1016/j. psj.2020.06.023

Roche, K. C., Gracz, A. D., Liu, X. F., Newton, V., Akiyama, H., and Magness, S. T. (2015). SOX9 maintains reserve stem cells and preserves radioresistance in mouse small intestine. Gastroenterology 149, 1553-1563. doi: 10.1053/j. gastro.2015.07.004

Rubio, L. A. (2019). Possibilities of early life programming in broiler chickens via intestinal microbiota modulation. Poult. Sci. 98, 695-706. doi: 10.3382/ ps/pey416

Shyer, A. E., Tallinen, T., Nerurkar, N. L., Wei, Z., Gil, E. S., Kaplan, D. L., et al. (2013). Villification: how the gut gets its villi. Science 342, 212-218. doi: $10.1126 /$ science. 1238842

Sklan, D. (2001). Development of the digestive tract of poultry. World Poul. Sci. J. 57, 415-428. doi: 10.1079/WPS20010030

Sklan, D., Prag, T., and Lupatsch, I. (2004). Structure and function of the small intestine of the tilapia Oreochromis niloticus $\mathrm{x}$ Oreochromis aureus (Teleostei, Cichlidae). Aquac. Res. 35, 350-357. doi: 10.1111/j.1365-2109.2004.01020.x

Speier, J. S., Yadgary, L., Uni, Z., and Wong, E. A. (2012). Gene expression of nutrient transporters and digestive enzymes in the yolk sac membrane and small intestine of the developing embryonic chick. Poult. Sci. 91, 1941-1949. doi: 10.3382/ps.2011-02092

Storch, J., and Corsico, B. (2008). The emerging functions and mechanisms of mammalian fatty acid-binding proteins. Annu. Rev. Nutr. 28, 73-95. doi: 10.1146/annurev.nutr.27.061406.093710

Takahashi, H., Hyodo, S., Abe, T., Takagi, C., Grau, G. E., and Sakamoto, T. (2014). Effects of fasting and refeeding on intestinal cell proliferation and apoptosis in hammerhead shark (Sphyrna lewini). J. Coast. Life Med. 2, 253-258. doi: 10.12980/JCLM.2.201414J17 
Tamaoki, K., Okada, R., Ishihara, A., Shiojiri, N., Mochizuki, K., Goda, T., et al. (2016). Morphological, biochemical, transcriptional and epigenetic responses to fasting and refeeding in intestine of Xenopus laevis. Cell Biosci. 6:2. doi: 10.1186/s13578-016-0067-9

Tarachai, P., and Yamauchi, K. (2000). Effects of luminal nutrient absorption, intraluminal physical stimulation, and intravenous parenteral alimentation on the recovery responses of duodenal villus morphology following feed withdrawal in chickens. Poult. Sci. 79, 1578-1585. doi: 10.1093/ps/79.11.1578

Uni, Z., Geyra, A., Ben-Hur, H., and Sklan, D. (2000). Small intestinal development in the young chick: crypt formation and enterocyte proliferation and migration. Br. Poult. Sci. 41, 544-551. doi: 10.1080/00071660020009054

Uni, Z., Noy, Y., and Sklan, D. (1999). Posthatch development of small intestinal function in the poult. Poult. Sci. 78, 215-222. doi: 10.1093/ps/78.2.215

Uni, Z., Platin, R., and Sklan, D. (1998). Cell proliferation in chicken intestinal epithelium occurs both in the crypt and along the villus. J. Comp. Physiol. B. 168, 241-247. doi: 10.1007/s003600050142

Uni, Z., Smirnov, A., and Sklan, D. (2003a). Pre- and post-hatch development of goblet cells in the broiler small intestine: effect of delayed access to feed. Poult. Sci. 82, 320-327. doi: 10.1093/ps/82.2.320

Uni, Z., Tako, E., Gal-Garber, O., and Sklan, D. (2003b). Morphological, molecular, and functional changes in the chicken small intestine of the late-term embryo. Poult. Sci. 82, 1747-1754. doi: 10.1093/ps/82.11.1747

Verdile, N., Mirmahmoudi, R., Brevini, T. A. L., and Gandolfi, F. (2019). Evolution of pig intestinal stem cells from birth to weaning. Animal 13, 2830-2839. doi: 10.1017/S1751731119001319

Verdile, N., Pasquariello, R., Scolari, M., Scirè, G., Brevini, T., and Gandolfi, F. (2020). A detailed study of rainbow trout (Onchorhynchus mykiss) intestine revealed that digestive and absorptive functions are not linearly distributed along its length. Animals 10:745. doi: 10.3390/ani10040745

Wang, F., Flanagan, J., Su, N., Wang, L., Bui, S., and Nielson, A. (2012). A novel in situ RNA analysis platform for formalin-fixed, paraffin-embedded tissues. J. Mol. Diagn. 14, 22-29. doi: 10.1016/j.jmoldx.2011.08.002

Wang, L., Li, J., Li, J. Jr., Li, R. X., Lv, C. F., Li, S., et al. (2016). Identification of the paneth cells in chicken small intestine. Poult. Sci. 95, 1631-1635. doi: $10.3382 / \mathrm{ps} /$ pew079

Wieck, M. M., Schlieve, C. R., Thornton, M. E., Fowler, K. L., Isani, M., Grant, C. N., et al. (2017). Prolonged absence of mechanoluminal stimulation in human intestine alters the transcriptome and intestinal stem cell niche. Cell. Mol. Gastroenterol. Hepatol. 3, 367-388. doi: 10.1016/j.jcmgh.2016.12.008

Wilson, F. D., Cummings, T. S., Barbosa, T. M., Williams, C. J., Gerard, P. D., and Peebles, E. D. (2018). Comparison of two methods for determination of intestinal villus to crypt ratios and documentation of early age-associated ratio changes in broiler chickens. Poult. Sci. 97, 1757-1761. doi: 10.3382/ ps/pex349

Yadgary, L., Cahaner, A., Kedar, O., and Uni, Z. (2010). Yolk sac nutrient composition and fat uptake in late-term embryos in eggs from young and old broiler breeder hens. Poult. Sci. 89, 2441-2452. doi: 10.3382/ ps.2010-00681

Zhang, S., Peng, X., Fang, J., Cui, H., Zuo, Z., and Chen, Z. (2014). Effects of aflatoxin B1 exposure and sodium selenite supplementation on the histology, cell proliferation, and cell cycle of jejunum in broilers. Biol. Trace Elem. Res. 160, 32-40. doi: 10.1007/s12011-014-0009-5

Zhang, H., and Wong, E. A. (2017). Spatial transcriptional profile of PepT1 mRNA in the yolk sac and small intestine in broiler chickens. Poult. Sci. 96, 2871-2876. doi: 10.3382/ps/pex056

Zhang, H., and Wong, E. A. (2018). Identification of cells expressing OLFM4 and LGR5 mRNA by in situ hybridization in the yolk sac and small intestine of embryonic and early post-hatch chicks. Poult. Sci. 97, 628-633. doi: $10.3382 / \mathrm{ps} / \mathrm{pex} 328$

Zwarycz, B., and Wong, E. A. (2010). Expression of the peptide transporters PepT1, PepT2, and PHT1 in the embryonic and posthatch chick. Poult. Sci. 2, 1314-1321. doi: 10.3382/ps.2012-02826

Conflict of Interest: The authors declare that the research was conducted in the absence of any commercial or financial relationships that could be construed as a potential conflict of interest.

Copyright (C) 2020 Reicher, Melkman-Zehavi, Dayan and Uni. This is an open-access article distributed under the terms of the Creative Commons Attribution License (CC BY). The use, distribution or reproduction in other forums is permitted, provided the original author(s) and the copyright owner(s) are credited and that the original publication in this journal is cited, in accordance with accepted academic practice. No use, distribution or reproduction is permitted which does not comply with these terms. 